\title{
De novo Drug Delivery Modalities for Treating Damaged Hearts: Current Challenges and Emerging Solutions
}

\author{
Syed Baseeruddin Alvi ${ }^{1}$, Salmman Ahmed ${ }^{1}$, Divya Sridharan ${ }^{1}$, Zahra Naseer ${ }^{1}$, \\ Nooruddin Pracha ${ }^{1}$, Henry Wang ${ }^{1}$, Konstantinos Dean Boudoulas ${ }^{2}$, Wuqiang Zhu ${ }^{3}$, \\ Nazish Sayed ${ }^{4}$ and Mahmood Khan ${ }^{1 *}$
}

${ }^{1}$ Department of Emergency Medicine, The Ohio State University Wexner Medical Center, Davis Heart and Lung Research Institute, College of Medicine, Columbus, $\mathrm{OH}$, United States, ${ }^{2}$ Division of Cardiovascular Medicine, Department of Medicine, The Ohio State University Wexner Medical Center, Columbus, OH, United States, ${ }^{3}$ Department of Cardiovascular Diseases, Physiology and Biomedical Engineering, Mayo Clinic, Phoenix, AZ, United States, ${ }^{4}$ Division of Vascular Surgery, Department of Surgery, The Stanford Cardiovascular Institute, Stanford University, Stanford, CA, United States

OPEN ACCESS

Edited by:

Sanjiv Dhingra

University of Manitoba, Canada

Reviewed by:

Suresh Kumar Verma,

University of Alabama at Birmingham,

United States

Johnson Rajasingh,

University of Tennessee Health

Science Center (UTHSC)

United States

*Correspondence:

Mahmood Khan

mahmood.khan@osumc.edu

Specialty section

This article was submitted to Cardiovascular Biologics and

Regenerative Medicine,

a section of the journal

Frontiers in Cardiovascular Medicine

Received: 16 July 2021

Accepted: 31 August 2021

Published: 28 September 2021

Citation:

Alvi SB, Ahmed S, Sridharan $D$,

Naseer $Z$, Pracha $N$, Wang $H$, Boudoulas KD, Zhu W, Sayed N and

Khan M (2021) De novo Drug Delivery

Modalities for Treating Damaged

Hearts: Current Challenges and

Emerging Solutions.

Front. Cardiovasc. Med. 8:742315.

doi: 10.3389/fcrm.2021.742315
Cardiovascular disease (CVD) is the leading cause of mortality, resulting in approximately one-third of deaths worldwide. Among CVD, acute myocardial infarctions (MI) is the leading cause of death. Current treatment modalities for treating CVD have improved over the years, but the demand for new and innovative therapies has been on the rise. The field of nanomedicine and nanotechnology has opened a new paradigm for treating damaged hearts by providing improved drug delivery methods, specifically targeting injured areas of the myocardium. With the advent of innovative biomaterials, newer therapeutics such as growth factors, stem cells, and exosomes have been successfully delivered to the injured myocardial tissue, promoting improvement in cardiac function. This review focuses on three major drug delivery modalities: nanoparticles, microspheres, and hydrogels, and their potential for treating damaged hearts following an Ml.

Keywords: myocardial infarction, heart failure, drug delivery, nanoparticles, clinical trials

\section{INTRODUCTION}

Cardiovascular disease (CVD) affects approximately 30 million adults in the United States of America each year, resulting on average in 647,000 deaths (1). Myocardial infarction (MI) is one of the most common causes of CVD due to an insufficient blood supply to the myocardium that may lead to cardiomyocyte injury and death, resulting in left ventricular (LV) dysfunction and subsequent heart failure $(2,3)$. Currently, treatment of heart failure with reduced ejection fraction consists of medical management with beta-blockers, renin-angiotensin-aldosterone system inhibitors, angiotensin receptor neprilysin inhibitor, and sodium-glucose co-transporter inhibitors. These agents have pleomorphic effects that improve survival and, in certain cases promote LV reverse remodeling. Additionally, researchers have shown promising results with antiinflammatory agents that prevent pro-inflammatory cytokines like interleukin-1 (IL-1) that can ameliorate cardiac stress and avoid remodeling (4). However, these pharmacological agents have limited effects on cardiac repair and recovery. Therefore, cardiac resynchronization therapy, when indicated, should also be applied due to the beneficial effects on mortality and morbidity in select heart failure patients. 
In certain cases of significant coronary artery disease, revascularization may be required by percutaneous coronary intervention and/or coronary artery bypass grafting (CABG) surgery (5) to restore sufficient blood supply to the myocardium. However, these interventions are limited by their inability to induce localized angiogenesis to injured tissue (6) and ability to rejuvenate damaged tissue. Therefore, exploring newer therapies for localized and controlled angiogenesis of the damaged cardiac tissues becomes essential for cardiac tissue repair and recovery.

Growth factors are bioactive molecules that exhibit a paracrine effect on efferent cells, like endothelial and fibroblasts regulating the extracellular matrix (ECM) deposition (7). There has been a growing interest in identifying and exploring novel recombinant growth factors as possible candidates for tissue repair and regeneration $(8,9)$. However, clinical trials conducted on the efficacy of these molecules failed to produce clinically relevant results (10-12). Despite the bioactivity of growth factors, its clinical efficacy was not as expected due to its poor stability, biological half-life, target specificity, among others. This warrants newer formulations with enhanced stability and desired pharmacokinetic profile to achieve clinically relevant therapeutic outcomes. This review highlights the recent advances and strategies adopted to administer growth factors utilizing nanoparticles (NPs), microparticles (MPs), and hydrogels for cardiac repair (Figure 1) and relevant clinical studies.

\section{FABRICATION OF NANOPARTICLES AND MICROSPHERES}

Nanoparticles can be fabricated by various methods depending on the type of polymer and drug used. Most NPs used for drug delivery purposes are based on lipids or polymeric nanosystems such as DSPC, HSPC, PLA, and PLGA. These nanoparticles can be prepared by thin-film hydration techniques, solvent evaporation, and co-precipitation, respectively. However, more extensive fabrication techniques have been reviewed elsewhere (13-19). A variety of hydrophobic and hydrophilic therapeutics molecules can be encapsulated in these nanoparticles by the single or double emulsification method, respectively (20-23). In general, the hydrophobic drugs and polymers are dissolved in

\footnotetext{
Abbreviations: ACS, acute coronary syndrome; ADM-2, adrenomedullin-2; bFGF, basic fibroblast growth factor; BIO, 6-Bromoindirubin-3-oxime; BMSCs, bone marrow mesenchymal stem cells; CABG, coronary artery bypass grafting; CAT, catalase; CVD, cardiovascular diseases; ECM, extracellular matrix; EV, extracellular vesicles; FGF1, fibroblast growth factor-1; GMA, glycidyl methacrylate; hESCCMs, human embryonic stem cell-derived cardiomyocytes; hESC-ECs, human embryonic stem cell-derived endothelial cells; HGF, hepatocyte growth factor; IGF-1, insulin-like growth factor; IL-1, interleukin-1; IL-1 $\beta$, interleukin-1 $\beta$; IV, intravenous; LV, left ventricular; LVAD, left ventricular assist device; MI, myocardial infarction; NPGs, nanoporous gels; NPs, nanoparticles; NRG1, neuregulin-1; PDGF, platelet-derived growth factor; PEC, polyelectrolyte complex; PEG, polyethylene glycol; PEGDA, polyethylene glycol di acrylate; PEI, polyethyleneimnine; PFBT, poly(9,9-dioctylfluorene-alt-benzothiadiazole); PLA, polylactic acid; PLGA, poly(lactic-co-glycolic acid), POD, peroxidase; PVA, polyvinyl alcohol; ROS, reactive oxygen species; SDF-1 $\alpha$, stromal cellderived factor 1; Shh, sonic hedgehog; SOD, superoxide dismutase; TIMP-3, tissue inhibitor of metalloproteinases- 3 inhibitor; TPP, triphenylphospine; T $\beta 4$, thymosin beta 4, VEGF, vascular endothelial growth factor.
}

solvents like chloroform, diethyl ether to form a non-aqueous phase. To this, an aqueous phase containing a stabilizer is added and emulsified; later, the emulsion is subjected to sonication for size reduction and allowed to stir for solvent evaporation (24-28). The single emulsion evaporation method yields an excellent encapsulation of hydrophobic drugs. However, the therapeutic proteins that are used for cardiac regeneration are water-soluble and exhibit poor stability, thus encapsulating them into a nanosystem involves additional excipients like heparin, and albumin, trehalose (29-31). More importantly, the double emulsification method for encapsulation of therapeutic proteins exhibits higher encapsulation and enhanced stability of the nanosystem.

The microspheres can be fabricated by following similar techniques and using similar polymers; however, factors like homogenization speed, sonication time, the molecular weight of the polymers can significantly influence the size and homogeneity of the microspheres (32-35). It has been observed that despite optimizing these variables, the exquisite tuning of the microsphere's size has offered significant challenges. It is of great significance to obtain uniform microspheres, especially for cardiac application, as microsphere embolism can lead to micronecrosis in cardiac tissues (36). More recently, microfluidic-based approaches are gaining attention to prepare microspheres with a high degree of uniformity and size tunability $(37,38)$. However, large-scale preparation of the microspheres is one of the significant challenges of using microfluidics (37). These drug delivery systems can be characterized for the shape and size by employing scanning electron microscopy (SEM), transmission electron microscopy (TEM), dynamic light scattering (DLS), and nanoparticle tracking analysis (NTA).

\section{FABRICATION OF HYDROGELS}

Hydrogels are extensively employed for the purpose of drug delivery. In general, hydrogels are fabricated by crosslinking hydrophilic polymers forming microporous three-dimensional structures. The porosity of hydrogels can be controlled by changing the degree of crosslinking, thereby influencing the rate of drug release. More importantly, hydrogels can entrap hydrophilic therapeutic proteins with high efficiency and exhibit sustained release as needed. A variety of hydrogels have been reported in the literature for various applications ranging from drug delivery, stem cell delivery, scaffolds to implants. Fabrication techniques for these hydrogels have been discussed elsewhere with extensive details. However, this review highlights the fabrication of a few smart hydrogels employed for cardiovascular applications.

Hydrogels have been broadly categorized into two, i.e., hydrogels derived from natural sources like polysaccharides, proteins, and hydrogels derived from synthetic sources like polyethylene glycol (PEG). These hydrogels can further be modified by conjugating molecules on the activated functional groups present on the polymer by click-chemistry approaches. Functionalization of these polymers imparts newer functionalities to the hydrogel, like $\mathrm{pH}$ or temperature 


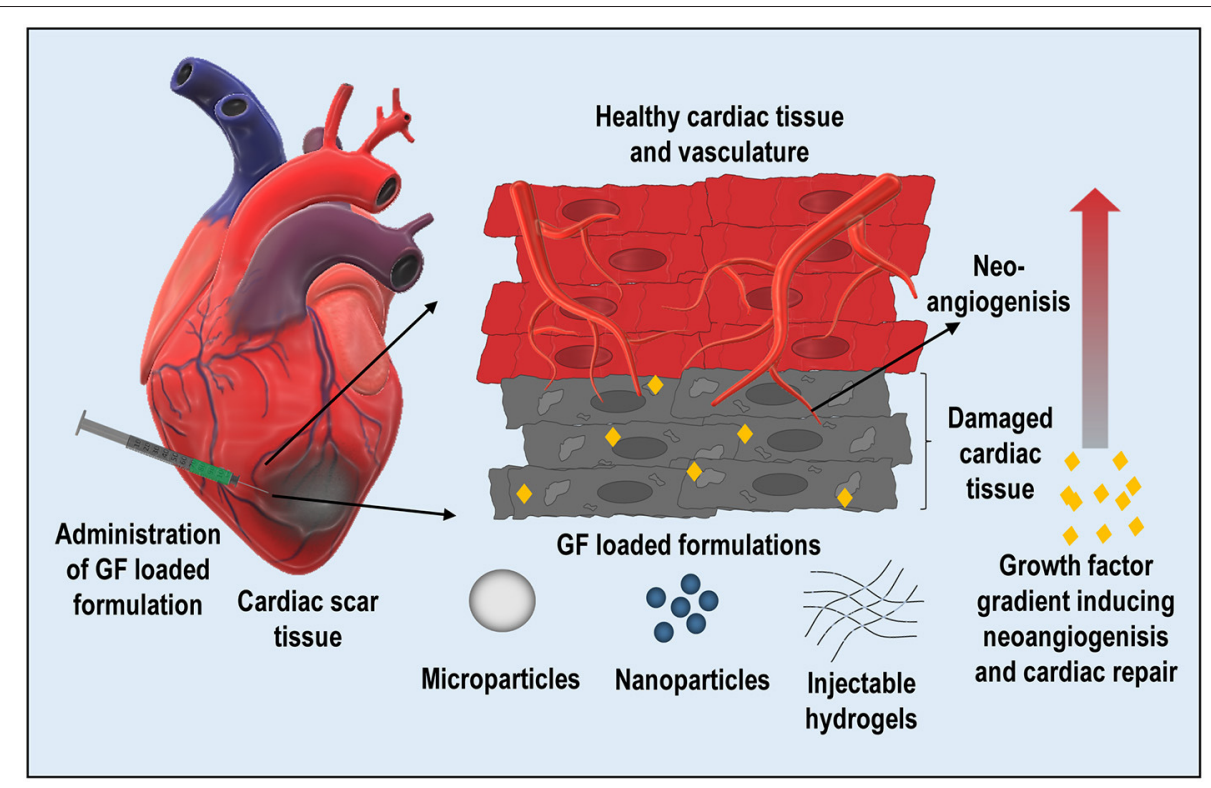

FIGURE 1 | Schematic representing the intramyocardial delivery of growth factor-loaded formulations (nanoparticles, microspheres, and hydrogels) for localized and sustained delivery for repairing the damaged cardiac tissue.

responsiveness, thus rendering them smart hydrogels. Researchers have used naturally occurring alginate that exhibits properties like shear thinning, excellent biocompatibility, and the ability to encapsulate living cells for cardiovascular and wound healing applications. The $-\mathrm{OH}$ group present on the alginate is oxidized by using oxidizing agents like sodium peroxide leading to the formation of alginate dialdehyde $(39,40)$. The aldehyde functional groups on alginate have been crosslinked with $-\mathrm{NH}_{2}$ groups present on gelatin, forming self-crosslinked hydrogels to deliver growth factors and stem cells. Similarly, gellan gum, a naturally occurring polysaccharide, has been used to fabricate biomimetic scaffolds for cardiac cells. The hydrogel scaffold was first fabricated by oxidizing - $\mathrm{OH}$ groups present on gellan by sodium periodate, leading to aldehyde functionalized gellan. Later, the modified gellan was crosslinked with gelatin forming hydrogel scaffold $(41,42)$. In a similar line, chitosan has also been used as a thermosensitive polymer for various tissue engineering applications (43). Biocompatible crosslinkers like tri-polyphosphate and $\beta$-glycerophosphate can easily crosslink and impart temperature responsiveness rendering them injectable $(44,45)$. Furthermore, self-assembling peptidebased injectable hydrogels have demonstrated immense potential for clinical application. Briefly, these self-assembling peptides with repeating units like "AEAEAKAKAEAEAKAK" can be synthesized using a solid-phase peptide synthesis technique on a substrate $(46,47)$.

Synthetic polymer-based hydrogels display versatile properties with a high degree of tunability. One of the most commonly used polymers for tissue engineering and drug delivery applications is polyethylene glycol (PEG) (48). The functionalization of PEG imparts newer properties to the hydrogel, and the most commonly used is methacrylate derivitization. Polyethylene glycol diacrylate (PEGDA) is a biocompatible, light-responsive polymer that undergoes crosslinking in the presence of a radical initiator (49). The crosslinking is facilitated by the UV/visible light irradiation, and the so formed hydrogel exerts mechanical stability, which can be used for encapsulating cells. PEGDA can be synthesized by a onepot microwave-assisted technique where methacrylic anhydride is mixed with PEG and subjected to microwave irradiation for 5 min, resulting in PEGDA (50). Similarly, polyvinyl alcohol (PVA) has also been functionalized with glycidyl methacrylate (GMA) to impart photocrosslinking of PVA. The -OH group on PVA was reacted with GMA in the presence of sulfuric acid at elevated temperature $\left(80-100^{\circ} \mathrm{C}\right)$; the resultant polymer was precipitated in acetone (51).

\section{NANOPARTICLES MEDIATED DELIVERY}

To overcome the challenges faced by conventional drug delivery, nanoparticle-based formulations have been evolved. Nanoparticle formulations can encapsulate the therapeutic cargo and deliver it to the specific tissue, which gives NPs an edge over the conventional formulation. In addition, recent advancements in nanotechnology have led to developing newer materials for tissue-specific delivery ranging from organic (polymers, lipids, proteins, among others) to inorganic (gold, iron, silica, among others) materials $(52,53)$. These nanosystems have shown enormous potential in treating cancers due to their ability to target tissues. However, in recent times they are also being explored in treating other diseases.

For the delivery of bioactive molecules to damaged cardiac tissue, a substantial amount of research has focused on developing nanoparticles that can precisely deliver the 
TABLE 1 | Studies highlighting the nanoparticle based formulations delivering therapeutics like miRNA, proteins and small molecules for cardiac repair.

\begin{tabular}{|c|c|c|c|c|}
\hline Authors & Therapeutics & Materials & Outcomes & References \\
\hline Liu et al. & Exosomes & $\begin{array}{l}\text { Fe304 core, silica shell, } \\
\text { polyethylene glycol }\end{array}$ & $\begin{array}{l}\text { Angiogenesis and improved heart function } \\
\text { in the infarcted region of heart }\end{array}$ & $(54)$ \\
\hline $\begin{array}{l}\text { Krohn-Grimberghe } \\
\text { et al. }\end{array}$ & SiRNA & $\begin{array}{l}\text { Polyethylene lipid } \\
\text { conjugates }\end{array}$ & $\begin{array}{l}\text { Decrease leukocytes, improved healing, } \\
\text { and prevented heart failure in diseased } \\
\text { heart }\end{array}$ & $(55)$ \\
\hline O’Dwyer et al. & $\begin{array}{l}\text { Stromal-Derived Factor } \\
1 \alpha(\mathrm{SDF})\end{array}$ & $\begin{array}{l}\text { Poly(glutamic acid) } \\
\text { (PGA) polypeptides }\end{array}$ & $\begin{array}{l}\text { Gap closure on the scratch assay, } \\
\text { increase in tubule length on Matrigel assay }\end{array}$ & $(56)$ \\
\hline Mohtavinejad et al. & $\begin{array}{l}\text { Diagnosing myocardial } \\
\text { infarctions at early } \\
\text { stages }\end{array}$ & $\begin{array}{l}\text { Polyethylene glycol } \\
\text { diacid }\end{array}$ & $\begin{array}{l}\text { Diagnosing a myocardial infarction at an } \\
\text { early stage at a low cost and low toxicity }\end{array}$ & $(57)$ \\
\hline Sayed et al. & miRNAs & $\begin{array}{l}\text { G poly(amidoamine)- } \\
\text { histidine } \\
\text { (PAMAM-His) }\end{array}$ & $\begin{array}{l}\text { The antiapoptotic effect, prevented } \\
\text { hypoxia/reperfusion-induced apoptosis }\end{array}$ & $(58)$ \\
\hline Li et al. & Peurarin & $\begin{array}{l}\text { Triphenylphosphonium } \\
\text { (TPP) cation }\end{array}$ & $\begin{array}{l}\text { Decrease in apoptotic cells and ROS } \\
\text { levels. Micelles can also be targeted to } \\
\text { ischemic region }\end{array}$ & (59) \\
\hline Guo et al. & $\begin{array}{l}\text { Tanshinone and } \\
\text { Puerarin }\end{array}$ & $\begin{array}{l}\text { Methoxy polyethylene } \\
\text { glycol }\end{array}$ & Cardioprotective mechanisms & $(60)$ \\
\hline Chen et al. & Stem Cell Therapy & Silica-iron oxide & $\begin{array}{l}\text { Increase in LV ejection fraction, } \\
\text { improvement in stem cell survival }\end{array}$ & $(61)$ \\
\hline Yokoyama et al. & $\begin{array}{l}\text { Adipose-derived stem } \\
\text { cell therapy }\end{array}$ & $\begin{array}{l}\text { Poly(lactic-co-glycolic) } \\
\text { acid PLGA }\end{array}$ & $\begin{array}{l}\text { Cardiac regeneration after a myocardial } \\
\text { infarction }\end{array}$ & $(62)$ \\
\hline
\end{tabular}

therapeutics to the targeted tissue, as shown in Table 1. One of the main reasons for adopting nanoparticles for drug delivery is the size of the material and the ability to target specific tissues by employing site-specific ligands. With the ease of surface functionalization and click chemistry, various targeting ligands can be grafted onto the NPs that limit the off-target toxicity. One successful strategy to deliver the therapeutics to the damaged myocardium is by targeting the damaged extracellular matrix (ECM). Huang et al. have reported a polylactic acid (PLA) conjugated with a shot peptide (cys-arg-glu-lys-ala, a clot binding peptide) to deliver thymosin beta 4 (T $\beta 4)$ for cardiac repair. This study investigated the possibility of targeting fibrin deposited in the damaged myocardium to deliver therapeutic peptides effectively. The results demonstrated sustained retention of the NPs within the injured myocardium for 7 days post intravenous (IV) administration and a significant reduction in scar tissue (63).

As the nanoparticle's size decreases, the effective surface area that can be used for grafting the molecules of interest increases substantially. Chang et al. reported the effect of poly(lactic-coglycolic acid) (PLGA) NP's size on payload retention. Insulinlike growth factor (IGF-1) was employed for its cardioprotective effect. The results demonstrated that $60 \mathrm{~nm}$ PLGA-NPs exhibited a higher loading efficiency and were successfully retained at the injected site for $24 \mathrm{~h}(\mathrm{~h})$ post-intramyocardial delivery. The in vivo study showed inhibition of scar formation and ventricular remodeling, thus displaying the cardioprotective nature of these NPs (64).

Following an acute MI, the inflammatory response leads to the recruitment of pro-inflammatory macrophages and myofibroblasts at the infarcted site; this results in scar formation, leading to LV dysfunction. Nanoparticle-based therapies targeting and modulating these inflammatory cells' responses can present a promising approach for preventing scar formation. Tokutome et al. have reported PLGA-NPs entrapping pioglitazone for tuning the localized immune response by IV administration following a MI. This study's rationale was to inhibit the activation of macrophages to the M1 phenotype (proinflammatory). When entrapped in PLGA-NPs, pioglitazone was selectively delivered to the macrophages (both local and splenic) and prevented the activation of macrophages, thus providing an anti-inflammatory response. The results demonstrated enhanced LV functioning and minimized scar formation. Furthermore, PLGA and pioglitazone's use imparts a more significant advantage as they are Food and Drug Administration approved and holds immense potential for clinical translation (65).

Nanoparticle-based therapies have also been explored for inducing angiogenesis; Ruvinov et al. reported polyelectrolyte complex NPs of cationic angiogenic growth factors complexed with anionic alginate sulfate. These nanoparticles showed significant improvement in LV functioning and superior angiogenesis (66). Quadros et al. also reported PLGA-NPs encapsulating adrenomedullin-2 (ADM-2), a proangiogenic and cardioprotective peptide. A sustained release was observed lasting for $\sim 21$ days while inducing endothelial cell growth when tested in vitro. These reports demonstrated the feasibility of using NPs for collateral angiogenesis in the damaged myocardium (67). Izadifar et al., reported a hybrid lipid-based nanoparticle encapsulating a cocktail of growth factors containing plateletderived growth factor (PDGF), vascular endothelial growth factor (VEGF), and basic fibroblast growth factor (bFGF). The bilayered nanoparticle encapsulating the growth factors 
exhibited a controlled release that could be employed for cardiac regeneration (68). Furthermore, Imanishi et al. have used morphogen sonic hedgehog (Shh) that has a great potential for tissue repair and regeneration post-MI, but the poor pharmacokinetic profile limits its applicability. To address this, a polyelectrolyte complex (PEC) was formulated that could encapsulate Shh and could be used for safe delivery to the myocardium. The study demonstrated a sustained release for up to 3 weeks resulting in the repair of cardiomyocytes (69).

Nanoparticles have also been used for gene transfection in vivo; the nonmetric size enhances cell penetration and transfection. As the genetic material exhibits a strong negative charge, it is often complexed with the positively charged NPs. Lin et al. have reported a smart hybrid system whose core was comprised of an antioxidant and was further coated with positively charged polymer in a layer-by-layer fashion. The surface of the nanoparticles were then complexed with plasmid DNA. The rationale of the study was combining the cytoprotective effect of melatonin (present in the core) along with hypoxia/normoxia responsive VEGF plasmid DNA (Figure 2). The smart NPs presented as an environmentresponsive nanosystem that triggers VEGF in hypoxic conditions make it a viable system for both acute and chronic cardiac repair (70). Additionally, Ye et al. reported a similar hypoxiaresponsive VEGF plasmid complexed with polyethyleneimine (PEI) for the transfection of skeletal myoblast. These NPs exhibited superior transfection efficacy, and the transfected cells showed enhanced VEGF expression under hypoxic conditions. When tested in vivo, a significant enhancement in LV functioning was observed (71).

One of the primary factors for myocardial cell death during ischemia is reperfusion injury. The first-line therapy for alleviating the myocardial ischemia is to perform reperfusion. However, an increase in intracellular reactive oxygen species (ROS) resulting from reperfusion surpasses the normal cell's antioxidant mechanism, thus causing cell death. To prevent ischemic injury, attempts have been made to fabricate enzymes mimicking NPs as a possible route to myocardial salvage. Zhang et al. fabricated a biomimetic artificial nanozyme that mimics the activities of enzymes like superoxide dismutase (SOD), catalase (CAT), and peroxidase (POD). These nanozymes target mitochondria by triphenylphosphine (TPP) and result in a significant quenching of ROS in the ischemic region following IV administration with subsequent improvement in LV functioning (72).

\section{MICROSPHERE BASED DELIVERY}

Microspheres bring a whole different paradigm to the world of drug delivery due to their relatively small size and other unique properties such as improved drug release kinetics and stability. As microspheres hold a larger volume than NPs, they can encapsulate various drugs and exhibit sustained release. Different polymers have been explored for the fabrication of MPs, including natural (alginate, chitosan, starch, among others) and synthetic (PLGA, Polycaprolactone (PCL), PLA, among others)
(Table 2). They can encapsulate small molecules, therapeutic peptides, and proteins and have been explored as a therapeutic modality for myocardial repair. In order to exert a therapeutic effect, the microparticles must retain within the myocardium for an extended period of time, enabling a sustained and localized delivery of bioactive materials. In a similar line, Formiga et al. has investigated the retention of PLGA based MPs with varying sizes $(2-30 \mu \mathrm{m})$; among these various sizes, $5 \mu \mathrm{m}$ showed the highest compatibility and myocardial retention for up to 3 months post intramyocardial delivery suggesting the use of MPs for myocardial regeneration (79).

The acute inflammatory response followed by MI often results in LV remodeling, and attempts have been made to inhibit this inflammatory response as a possible treatment. Pro-inflammatory cytokines like IL- $\beta$ are released following myocardial cell damage. Thus, IL- $\beta$ inhibitors potentially can serve as a therapeutic target; however, IL- $\beta$ inhibitors, due to their systemic inhibition of IL- $\beta$, results in fatal adverse events. In an attempt to mitigate adverse systemic effects, they have been delivered locally using MPs. Li et al. reported a platelet mimicking MPs grafted with anti-IL-1 $\beta$ for a localized antiinflammatory response. The study's rationale was to target the infarcted region by platelet-derived membranes that were grafted with anti-IL-1 $\beta$. The in vivo results indicated specific localization of the microparticles within $8 \mathrm{~h}$ of injection, which lasted for $72 \mathrm{~h}$. It showed a sustained targeting ability of the microsystem essential to inhibit the acute inflammatory response following an MI. Moreover, the same microparticles showed no accumulation in cardiac tissue when injected in normal mice, further proving its targeting efficacy during MI (80).

Cardiac stem cells mimicking MPs were reported by Tang et al., and the rationale of this study was to mimic the paracrine and cell-cell adhesion properties of stem cells. This was achieved by fabricating a PLGA core entrapping growth factors like VEGF, insulin-like growth factor 1 (IGF-1), and hepatocyte growth factor (HGF) that were released in a sustained manner (Figure 3). The same growth factor releasing cargo was coated with stem cell-derived membranes, mimicking both paracrine factors (growth factors) and cell-cell interaction (by membrane coating) of stem cells. Being an acellular approach, one of the major advantages of this is the lack of immune rejection, which is otherwise evident in stem cell implantation. Moreover, when injected intramyocardially following a MI, a reduction in scar size and enhanced angiomyogenesis was observed (81). This presents a newer acellular approach for remuscularization of infarcted myocardium as a possible therapeutic strategy.

The inflammatory response following MI is induced by infiltrating pro-inflammatory macrophages within the infarcted region. It has been reported that macrophage polarization toward a reparative phenotype could prevent inflammation and repair the damaged tissues. Pascual-Gil et al. used polymer-based MPs as a way to achieve sustained and local delivery, specifically to the damaged heart focusing on the relationship between neuregulin-1(NRG-1) loaded PLGA-MPs and inflammation. They discovered that the intramyocardial delivery of NRG-1 PLGA-MPs improved the immune response post-MI. Interestingly, when these MPs were administered at 


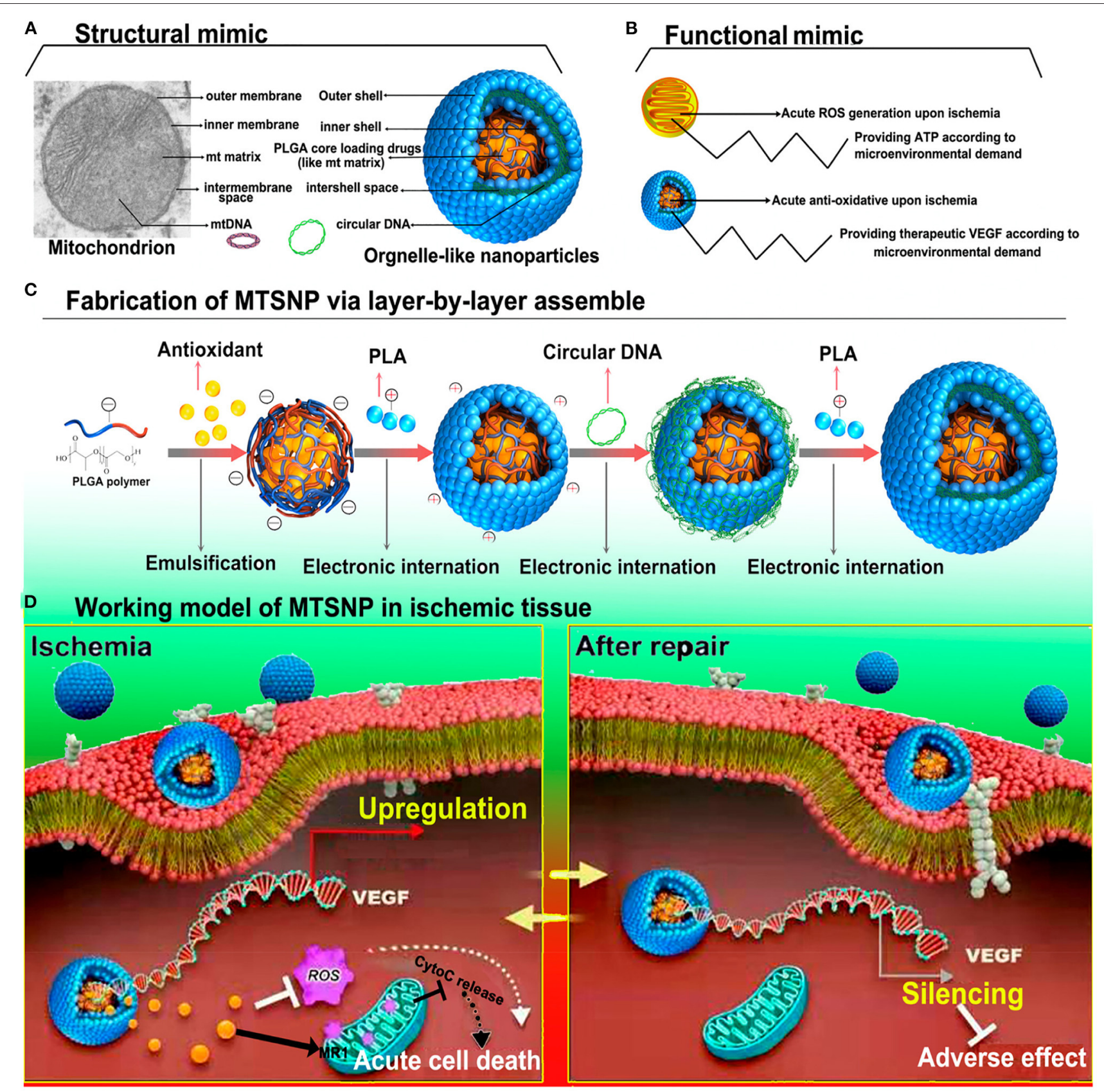

FIGURE 2 | Schematics representing the fabrication of mitochondria mimicking smart polyelectrolyte nanoparticle and their mechanism of action. (A) Structural mimic of organelle-like nanoparticle, (B) Functional similarity of the mitochondrion and organelle-like nanoparticle. (C) Fabrication of organelle-like nanoparticles by layer-by-layer approach. (D) Ischemia responsive activation of VEGF expression facilitated organelle-like nanoparticle and their antioxidant potential (70).

various time points, they were shown to improve the antiinflammatory response post-MI (82).

NRG-1 and fibroblast growth factors (FGF) typically have a shorter half-life and do not have a specified target. However, the pharmacokinetics of both of these growth factors can be significantly improved when used as MPs leading to enhanced bioavailability. Therefore, researchers have increasingly used MPs to deliver these growth factors to treat the infarcted regions postMI. Similarly, Formiga et al. have used the fibroblast growth factor-1 (FGF1) and NRG-1 growth factors encapsulated in PLGA-MPs and administered to the heart after an acute MI. Additionally, they were able to achieve a sustained release of the growth factors for a more extended period. Three months after intramyocardial administration of MPs, a significant reduction 
TABLE 2 | Microparticle based formulations used as a depot for sustained delivery of growth factors aiding in cardiac repair.

\begin{tabular}{|c|c|c|c|c|}
\hline Authors & Therapeutics & Materials & Outcomes & References \\
\hline Nie et al. & Nicotinamide riboside & Drug co-crystals & $\begin{array}{l}\text { Protection against acute heart injury with } \\
\text { no cytotoxic effects on any major organs }\end{array}$ & (73) \\
\hline Feng et al. & Insulin-like growth factor 1 & $\begin{array}{l}\text { Silk fibroin } \\
\text { microspheres }\end{array}$ & $\begin{array}{l}\text { Reduction of infarct size and overall } \\
\text { improvement of cardiac function }\end{array}$ & $(74)$ \\
\hline Zhang et al. & Endothelial growth factor & $\begin{array}{l}\text { poly(lactic-co-glycolic } \\
\text { acid) (PLGA) }\end{array}$ & $\begin{array}{l}\text { Enhanced proliferation of endothelial cells } \\
\text { and promoted capillary and smooth } \\
\text { muscle formation }\end{array}$ & $(75)$ \\
\hline Song et al. & Embryonic stem cells & $\begin{array}{l}\text { Poly- } \varepsilon \text {-caprolactone } \\
\text { (PCL) }\end{array}$ & $\begin{array}{l}\text { Microspheres aided in embryonic stem cell } \\
\text { differentiation which can be used for } \\
\text { delivery to the myocardium }\end{array}$ & $(76)$ \\
\hline Rodness et al. & $\begin{array}{l}\text { Vascular endothelial growth } \\
\text { factor (VEGF) }\end{array}$ & Calcium-alginate & $\begin{array}{l}\text { Improved cardiac function when } \\
\text { compared to control, but resulted in } \\
\text { thicker scars with high capillary density }\end{array}$ & $(77)$ \\
\hline Arunkumar et al. & $\begin{array}{l}\text { Basic Fibroblast Growth Factor } \\
\text { (bFGF) }\end{array}$ & PCL & Rapid angiogenesis in gel plug assay & (78) \\
\hline
\end{tabular}

in infarct size was seen with a lower rate of fibrosis than control (83) and improvement in overall cardiac function.

Microparticles have also been explored for the localized delivery of stem cells and engraftment, as reported by Savi et al. The MPs encapsulating hepatocyte growth factor (HGF) and insulin-like growth factor 1 (IGF-1) were fabricated and complexed with adipose-derived stem cells. They successfully formed a substrate for the cell attachment and, in addition to it, acted as a reservoir for sustained release of growth factors. When these cells and MPs complexes were administered into mice models, they exhibited localized stem cell retention that stimulated the healing of the infarcted myocardium and restored hemodynamics within the region. However, there is an unmet need to address the arrhythmias arising from cell engraftments (84). Additionally, Zhang et al. reported a combination of HGF with IGF-1 and its protective effect on implanted bone marrow mesenchymal stem cells (BMSCs) as a treatment modality for the damaged heart. When injected into the damaged myocardium, the growth factor-loaded MPs showed reduced apoptosis and enhanced myocardial differentiation resulting in improved LV function (85).

Madonna et al. have employed fibronectin-coated PLGAMPs encapsulating VEGF as a carrier for adipose tissuemesenchymal stromal cells. These microcarriers were injected into the infarcted region of the heart. Similarly, treatment with these MPs demonstrated improvement in LV function (86). In a similar study, Rosellini et al. reported biomimetic gellan/gelatin microspheres loaded with IGF-1 combined with cardiac progenitor cells for localized cell engraftment and sustained release of growth factors. The results demonstrated cardiac progenitor cell adhesion to the MP's surface. These microspheres also reduced myocardial damage and improved overall cardiac function and successful cell engraftment (87).

Following an MI, a drastic increase in the ROS levels is observed in both intracellular and extracellular environments. Thus, enriching the environment with antioxidant enzymes could be used as a therapeutic strategy. Seshadri et al. reported polyketal MPs encapsulating SOD1 quenching ROS both in the intracellular and extracellular environment. On the contrary, only extracellular ROS was quenched when the free enzyme was administered. Furthermore, once injected intramyocardially, the MPs were retained for 3 days in the myocardium and prevented myocardial cell death (88).

\section{HYDROGELS MEDIATED DELIVERY}

Hydrogels are one of the most extensively researched therapeutics for drug delivery and tissue engineering. They are composed of a crosslinked polymer network by forming covalent bonds, hydrogen bonds, and hydrophobic interactions between the polymer chains, thereby forming a depot (89). The use of biocompatible and biodegradable polymers to form a 3D matrix accommodating cells, drugs, NPs, MPs, or combinations has further expanded the applicability of hydrogels. A variety of hydrogels have been reported as a modality for repairing the injured myocardium (Table 3). However, the primary considerations in designing hydrogel for cardiac repair are its injectability and stable depot formation at the injected site. Significant improvements have been made in the design and materials for the hydrogels, which respond to stimuli like temperature, light, enzymes, $\mathrm{pH}$, among others. Some of the recent advancements in the field for myocardial repair are discussed in the following section.

The remodeling of the LV following an MI is the consequence of a cascade of inflammatory responses that activates ECM degrading enzymes. Attempts have been made to inhibit the activity of such enzymes from preventing cardiac remodeling after MI. Awada et al. has fabricated fibrin-based hydrogel entrapping polyelectrolyte complexes for myocardial repair. The rationale of the study was to avoid remodeling and to remuscularize the injured myocardium. To achieve this, metalloproteinases-3 inhibitor (TIMP-3) was entrapped in the fibrin matrix for rapid release and inhibition of ECM 
A

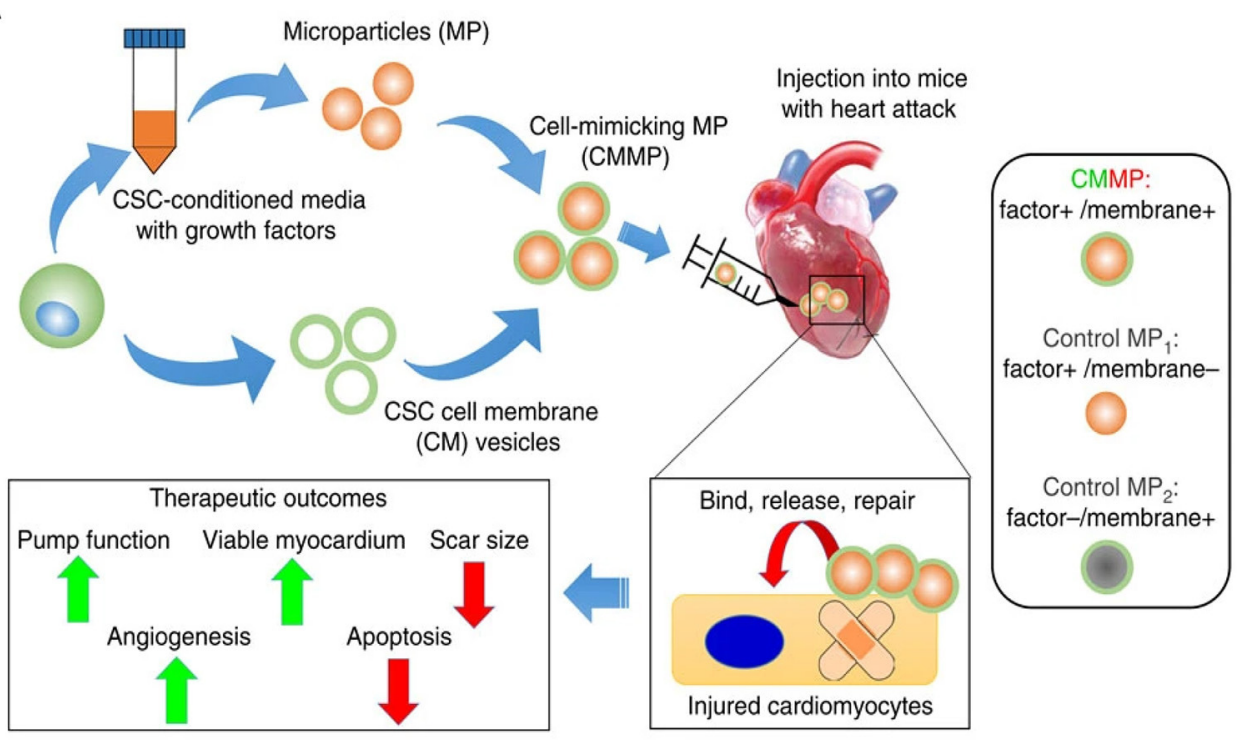

B

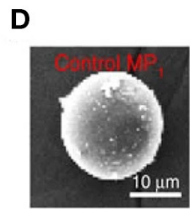

F
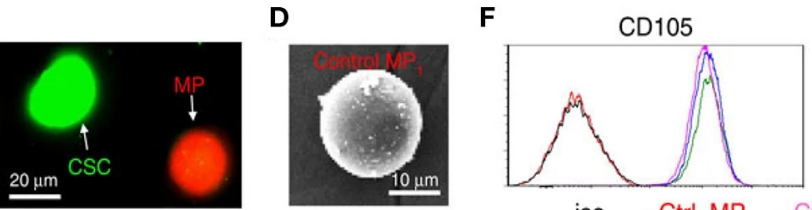

G

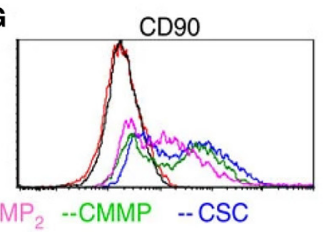

CSC membrane cloaking

C

E
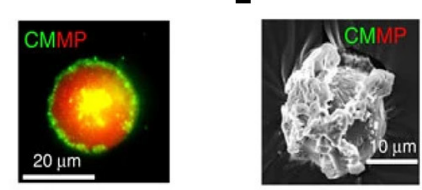

H

--- iso -- Ctrl. MP 1 -- Ctrl. MP $P_{2}$--CMMP $\quad$-- CSC

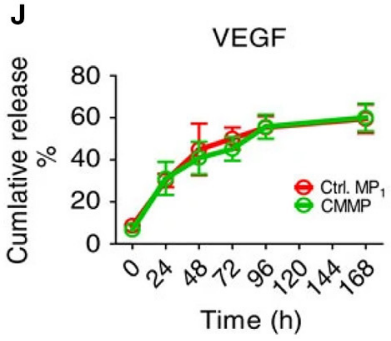

K

IGF-1
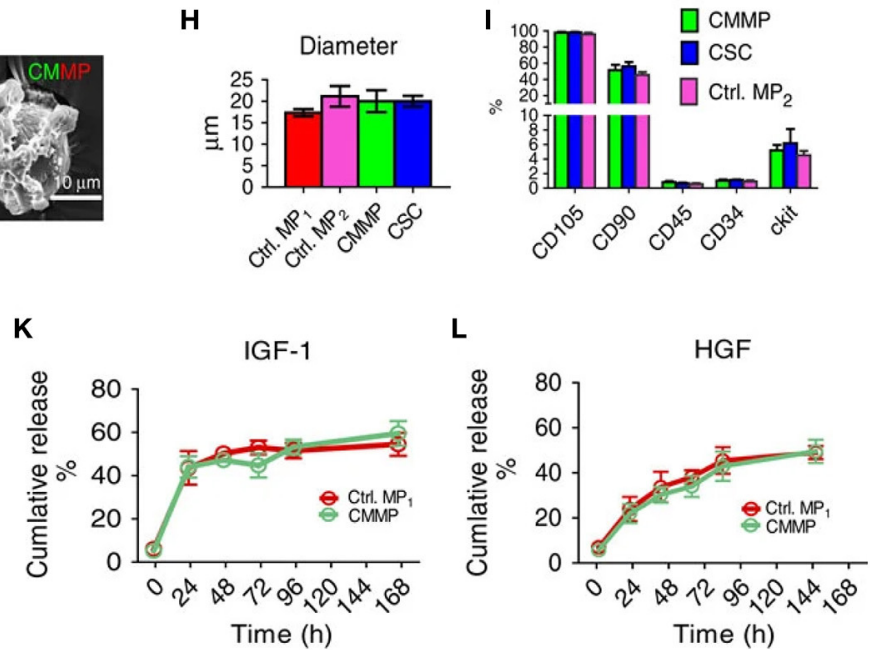

FIGURE 3 | (A) Schematic representing cardiac stem cell (CSC) mimicking microspheres fabricated by coassembly of CSC-derived membranes on polymeric microspheres. (B,C) Fluorescence imaging of CSC (green) and microsphere (red) tagged with fluorescent dyes (D,E) SEM of blank microsphere and CSC coated microsphere. (F,G) Evaluation of CSC markers on fabricated hybrid microspheres. (H) Size analysis of hybrid microspheres and respective controls. (I) CSC antigen analysis of hybrid microspheres. (J-L) VEGF, IGF-1, and HGF growth factors release profiles from the hybrid microspheres, respectively (81).

degradation. Secondly, for remuscularization, FGF-2 and stromal cell-derived factor 1 (SDF-1 $\alpha$ ) were formed into polyelectrolyte complexes for sustained release. Taken together, the timely release of these proteins from hydrogel showed significant improvement in cardiac functionality up to 8 weeks posttreatment (99).
The paracrine factors released from the stem cells have shown significant improvements in cardiac function. Tang et al. reported P(NIPAM-AA) based nanogels encapsulating cardiac stem cells for localized delivery to the myocardium. The stem cell embedded nanogels were injected in the immune-competent mice that showed no inflammatory immune response prolonging 
TABLE 3 | Studies highlighting the hydrogel formulations used to delivering cells, miRNA, small molecules and growth factors for cardiac repair.

\begin{tabular}{|c|c|c|c|c|}
\hline Authors & Therapeutics & Materials & Outcomes & References \\
\hline Shvartz et al. & Amiodarone & Sodium alginate & $\begin{array}{l}\text { Prevented postoperative atrial fibrillation post } \\
\text { coronary artery bypass surgery. }\end{array}$ & (90) \\
\hline Zhu et al. & $\begin{array}{l}\text { Induced pluripotent } \\
\text { stem cells }\end{array}$ & Extracellular matrix hydrogel & Robust cardiovascular repair post-Ml & (91) \\
\hline Malektaj et al. & Niosomal rosuvastatin & Poly (N-isopropyl acrylamide) (PNIPAAm) & Enhanced angiogenesis & (92) \\
\hline Radmanesh et al. & microRNAs & $\begin{array}{l}4 \text { arm PEG in combination with } \\
\text { polyelectrolyte complex }\end{array}$ & $\begin{array}{l}\text { Enhanced angiogenesis and enhancement of } \\
\text { capillary density }\end{array}$ & (93) \\
\hline Contessotto et al. & $\begin{array}{l}\text { Elastin-like } \\
\text { recombinamers }\end{array}$ & Extracellular matrix hydrogel & $\begin{array}{l}\text { Reduced fibrosis and more angiogenesis } \\
\text { occurring as well as preservation of } \\
\text { cardiomyocytes }\end{array}$ & $(94)$ \\
\hline Sim et al. & $\begin{array}{l}\text { Bone marrow-derived } \\
\text { mesenchymal stem } \\
\text { cells }\end{array}$ & Heart derived extracellular matrix hydrogel & $\begin{array}{l}\text { Improvement in cardiac function and protection } \\
\text { of myocardium }\end{array}$ & (95) \\
\hline Lyu et al. & $\begin{array}{l}\text { Human mesenchymal } \\
\text { stem cells }\end{array}$ & Hyaluronic acid hydrogel & $\begin{array}{l}\text { Decreased inflammatory response and } \\
\text { revascularization of the infarct region }\end{array}$ & (96) \\
\hline You et al. & $\begin{array}{l}\text { Mesenchymal stromal } \\
\text { cells }\end{array}$ & $\begin{array}{l}\text { Poly(2-alkyl-2-oxazoline) (POx) derivative, } \\
\text { based on 2-ethyl-2-oxazoline and } \\
\text { 2-butenyl-2-oxazoline }\end{array}$ & $\begin{array}{l}\text { Fibrosis reduction and improvement of overall } \\
\text { cardiac function as well as neovascular } \\
\text { formation }\end{array}$ & $(97)$ \\
\hline Ding et al. & $\begin{array}{l}\text { ROS scavenging and } \\
\mathrm{O}_{2} \text { generating gel }\end{array}$ & $\begin{array}{l}\text { 3s hyperbranched polymers and } \\
\text { methacrylate hyaluronic acid (HA-MA) }\end{array}$ & $\begin{array}{l}\text { Removal of excess ROS, reduction in infarct } \\
\text { size, inhibition of apoptotic cells }\end{array}$ & (98) \\
\hline
\end{tabular}

its retention, which otherwise was not observed with only stem cell injections. Results demonstrated a significant improvement in cardiac functionality and remuscularization when compared with only stem cell injections. More interestingly, the group treated with the only nanogel also showed considerable improvement, including scar inhibition, which could have been due to the formation of a physical barrier for immune cell infiltration suggesting the beneficial role of hydrogel (100). Among similar lines, Kanda et al. reported cocoonlike nanoporous gels (NPGs) and studied the effect of the varying NPG content. They found that by increasing NPG concentration, significant enhancement in cell migration and cytokine and extracellular vesicles (EV) secretion were observed. Taken together, these NPG's when administered in vivo were found to improve cardiac function and boosted the generation of new blood vessels (101).

Furthermore, Fang et al. have shown the potential of sustained delivery of 6-Bromoindirubin-3-oxime (BIO) and IGF-1 in a hybrid hydrogel system, which could help induce cardiac repair in vivo. The use of small molecules like BIO that promotes cell cycles in adult cardiomyocytes can aid in remuscularization. Both the BIO and IGF-1 were encapsulated within gelatin NPs. The results demonstrated that the hybrid gel material, when administered to MI-induced rats, showed proliferation of cardiac cells, enhanced revascularization around the infarcted area, and improved overall LV function (40).

The miRNA has shown promise in treating various diseases, including CVD. The limiting factor for miRNA-based therapies is the lack of cell internalization and delivery vehicles. Along similar lines, Yang et al. reported a poly(9,9-dioctylfluorenealt-benzothiadiazole) (PFBT) based miRNA delivery system. These NPs were loaded within a hydrogel matrix and administered intramyocardially. The miRNA was seen to trigger the proliferation of human embryonic stem cell-derived cardiomyocytes and endothelial cells (hESC-CMs and hESCECs), and promote angiogenesis during hypoxia with lower toxicity than other treatments. Following hydrogel injection, LV function was improved by increasing the ejection fraction from $45-64 \%$ and reducing scar size from $20-10 \%$ while doubling the capillary density. This introduced a mechanism to deliver miRNA to restore LV function (102).

Cardioprotective hydrogel based on crosslinked polyvinyl alcohol (PVA) has been reported by Li et al. The gel undergoes degradation when exposed to ROS. The advantage of using ROS-responsive hydrogels is that they can prevent ischemic reperfusion injury, where a burst of ROS is produced in response to reperfusion. More interestingly, the hydrogel can also release encapsulated cargo, like bFGF, in response to ROS. Furthermore, the authors have also demonstrated the feasibility of administering the hydrogel to the pericardial cavity in large animals and humans (Figure 4), resulting in significant improvement in $\mathrm{LV}$ function and enhanced angiogenesis (103).

The peptide-based hydrogels have opened up a newer array of biocompatible, self-assembled, and biodegradable materials. The primary advantage of a peptide hydrogel over others is the ability to tune the mechanical and chemical properties by altering the amino acid sequences. For example, Lin et al. reported a peptide hydrogel and employed it as a cell delivery material for cardiac repair. When the gel was injected into the myocardium of pigs following an acute MI resulting in heart failure, LV function was improved. More interestingly, the peptide gel alone was also able to show improvement in cardiac function. These findings agree with earlier reports suggesting that blank hydrogels themselves can impart therapeutic benefit and aid in repairing injured myocardium (104). 
A

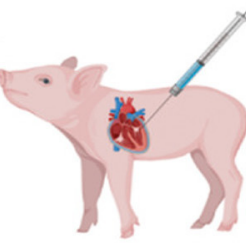

B

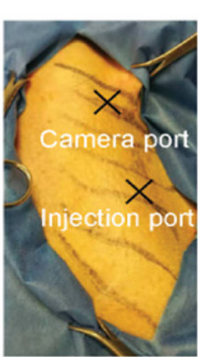

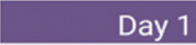

pre-Blood collecting; pre-Pericardial fluid collecting; Intrapericardial injection

C
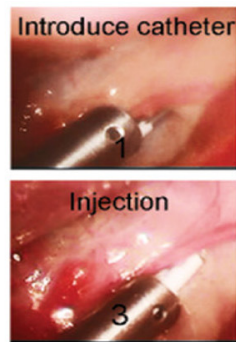

E

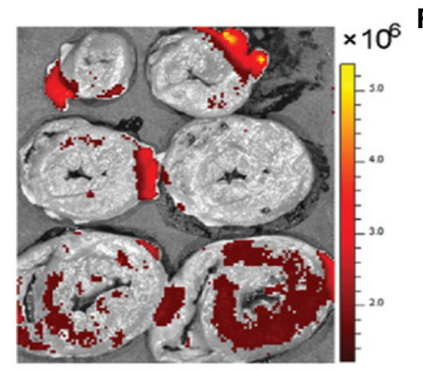

G

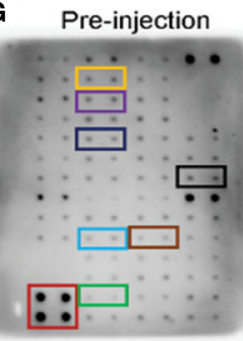

I

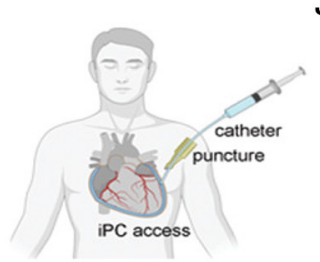

Post-injection

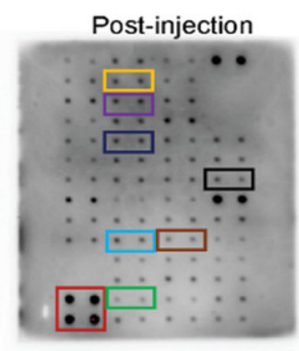

J

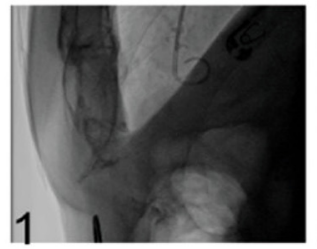

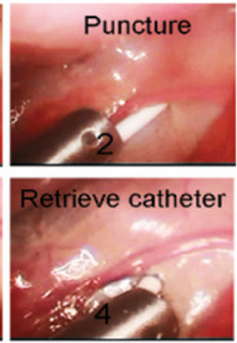

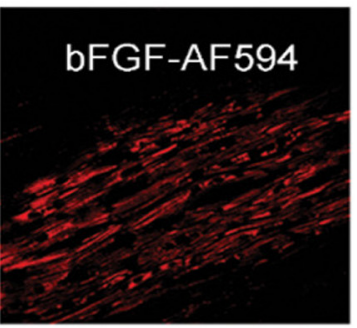

\section{Day 2}

(1)

post-Blood collecting post-Pericardial fluid collecting; Heart collecting

D
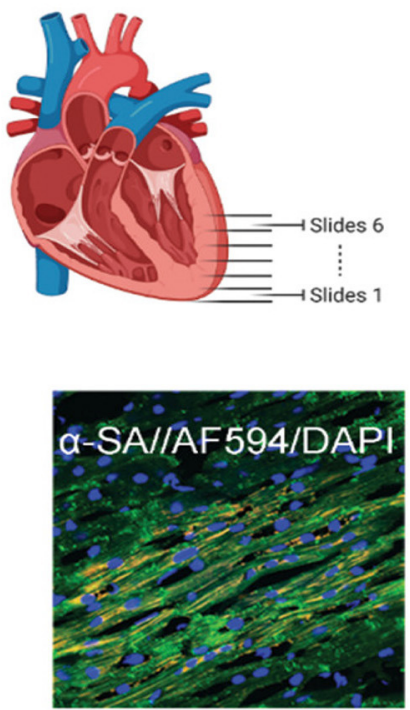

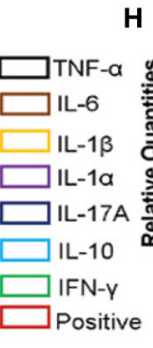

H $\quad 1.07 \square$ Pre-injection

- Post-injection
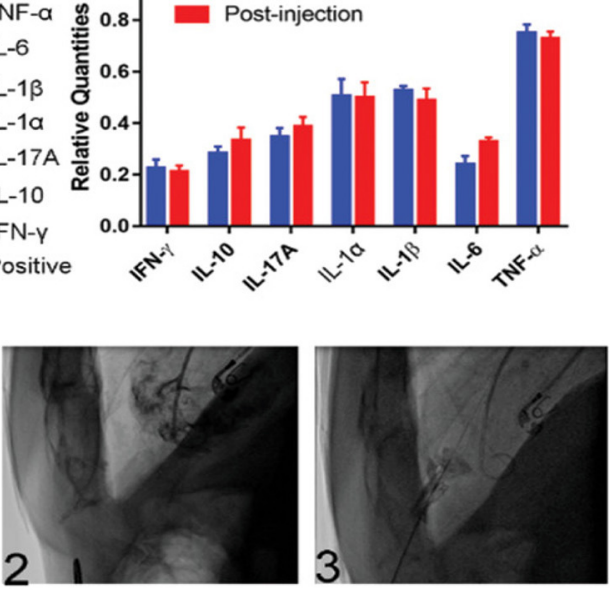

FIGURE 4 | (A) Schematics representing the protocol for large animal studies for smart hydrogel. (B) Photograph showing the position of the camera and an injection port. (C) Sequential representative images are displaying the administration of smart hydrogel. (D) Schematic representing the sectioning of the isolated heart. (E) Ex vivo NIR imaging of cardiac slices demonstrating the accumulation of injected smart hydrogel. (F) Fluorescence imaging of bFGF. (G,H) Quantitative and qualitative analysis of cytokines before and after administration of smart hydrogel. (I,J) The feasibility of minimally invasive catheter-based administration into the pericardial cavity in a human subject (103).

Similarly, Bai et al. combined bioactive ECM hydrogels and high cardiomyogenic seeding cells for cardiac repair. These hydrogels were shown to support proliferation and cardiomyogenic differentiation, all while improving overall cardiac function. These results were observed both in vitro and in vivo (105). Lastly, Dong et al. developed a conductive hydrogel that provides an excellent vehicle for cell delivery post-MI. This hydrogel also exhibited self-healing behavior and enhanced cardiac cell viability when entrapped in the gel matrix (106). 
TABLE 4 | Clinical studies conducted on nano/micro particles and hydrogels for cardiac related ailments.

\begin{tabular}{|c|c|c|c|}
\hline Clinical trials & Therapeutics & Type & Clinical trials ID \\
\hline $\begin{array}{l}\text { Magnetic Nanoparticles System in Acute Coronary } \\
\text { Syndrome }\end{array}$ & Magnetic nanoparticles for diagnostics & Nanoparticles & (NCT02226523) \\
\hline $\begin{array}{l}\text { Plasmonic Nanophotothermal Therapy of } \\
\text { Atherosclerosis (NANOM-FIM) }\end{array}$ & $\begin{array}{l}\text { Bioengineered cardiac patch to regress } \\
\text { atherosclerosis }\end{array}$ & Nanoparticles & (NCT01270139) \\
\hline $\begin{array}{l}\text { Treatment of Patients With Atherosclerotic Disease } \\
\text { With Methotrexate-associated to LDL Like } \\
\text { Nanoparticles }\end{array}$ & LDL binding Methotexate nanoparticles & Nanoparticles & (NCT04616872) \\
\hline $\begin{array}{l}\text { Microvascular Reperfusion Utilizing } \\
\text { Sonothrombolysis in Acute Myocardial Infarction } \\
\text { (MRUSMI TRIAL) (MRUSMI) }\end{array}$ & $\begin{array}{l}\text { Sonothrombolysis to break up blood clots } \\
\text { in arteries }\end{array}$ & Microspheres & (NCT02170103) \\
\hline Contrast ICE for myocardial Scar in VT Ablations & $\begin{array}{l}\text { Diagnostic echocardiography to visualize } \\
\text { scar tissue formation }\end{array}$ & Microspheres & (NCT03212326) \\
\hline $\begin{array}{l}\text { Autologous Human Cardiac-Derived Stem Cell to } \\
\text { Treat Ischemic cardiomyopathy (ALCADIA) }\end{array}$ & $\begin{array}{l}\text { Human cardiac derived stem cells and } \\
\text { bFgF for treating refractory heart failure }\end{array}$ & Hydrogel & (NCT00981006) \\
\hline First in Man Study of Implantable Alginate Hydrogel & $\begin{array}{l}\text { Implantable Alginate Hydrogel for left } \\
\text { ventricle reconstruction }\end{array}$ & Hydrogel & (NCT04781660) \\
\hline $\begin{array}{l}\text { COVADIS Pilot Trial: COseal in Ventricular Assist } \\
\text { Devices (COVADIS) }\end{array}$ & $\begin{array}{l}\text { Surgical hydrogel used to prevent cardiac } \\
\text { adhesions }\end{array}$ & Hydrogel & (NCT01244321) \\
\hline
\end{tabular}

\section{CLINICAL TRIALS}

A growing body of literature shows that a relatively large number of therapeutic modalities are being taken up for clinical testing for various illnesses like CVD, cancer, and wound healing. The clinical translation of newer research modalities is often challenged with stringent criteria to demonstrate the safety and efficacy of the formulations. However, there is a need to bridge the gap from bench to bedside, enabling researchers to develop clinically relevant and translatable therapeutics. In the following section, recent clinical studies conducted for cardiac theranostics involving NPs, MPs, and hydrogels (summarized in Table 4) are discussed.

Accurate and timely diagnosis of acute coronary syndrome (ACS) is of great clinical importance. Therefore, magnetic NPs surface-functionalized with bio-probes was developed for rapid detection of early ACS diagnostics markers (NCT02226523). The principle behind the technology is to assess the magnetic oscillation of the NPs when exposed to alternating current, as these NPs interact with biomarker protein from the blood samples retrieved from patients; it undergoes aggregation resulting in the reduction of magnetic oscillation events known as immunomagnetic reduction (107). Thus, this technique offers real-time, rapid detection of clinically relevant biomarkers that can aid in early MI diagnosis.

The formation of atherosclerotic plaque in the coronary arteries is considered a primary predisposing factor for MI. Nanoparticle-based therapies have been developed and tested for the eradication of atherosclerotic plaque. Silica-gold and $\mathrm{Fe}_{3} \mathrm{O}_{4}$ magnetic NPs have been used for photothermal ablation of atherosclerotic plaque both non-invasively and in a minimally invasive manner (NCT01270139). The NIR light used exhibits deep tissue penetration making it possible for irradiation from outside the body resulting in a remarkable reduction in atherosclerotic plaque compared with controls without adverse events. This has emerged as a newer paradigm in treating atherosclerotic plaque $(108,109)$. Sonothrombolysis is another new therapy that has also been explored to break down thrombus using ultrasound combined with perflutren lipid microspheres (NCT02170103). The ultrasound frequency within the range of 1-1.7 MHz has significantly reduced infarct size and provided regional functional recovery (110). It has also been demonstrated that perflutren lipid microspheres can be used for contrast imaging to identify foci responsible for ventricle tachycardia. The current clinical approach for treating ventricular tachycardia is by catheter-based ablation, which requires electrical mapping of ventricles to locate the foci; ultrasound-based tissue imaging could further identify potential arrhythmogenic foci within scar (NCT03212326). Therefore, researchers are using these lipidbased microspheres that could aid in the accurate diagnosis of arrhythmias.

The localized inflammatory response is one of the main driving factors in the formation of atherosclerotic plaque. Treatment with anti-inflammatory agents has shown some degree of inhibition in plaque progression (111). A lipid-based nanosystem mimicking LDL encapsulating methotrexate (as an anti-inflammatory agent, NCT04616872) has been tested. Clinically higher doses of methotrexate may result in severe systemic adverse events. However, by using nanoparticle-based targeted delivery, inflammatory lesions can be treated without developing off-target toxicities. Animal studies have shown the ability to inhibit pro-inflammatory cytokines while upregulating anti-inflammatory cytokines with a significant reduction in scar size (112).

Hydrogel entrapping bFGF has also been investigated in clinical studies. An implantable crosslinked gelatin hydrogel sheet was fabricated and investigated for improving the engraftment and survivability of injected stem cells 
(NCT00981006). The autologous cardiac stem cells were implanted in bFGF gelatin hydrogel sheets in patients with severe LV dysfunction. The results demonstrated a decrease in scarring, and a significant enhancement in LV functioning within 6 months of implantation, and improved exercise tolerance. Moreover, the clinical data suggest that this biotherapy can be safely administered to patients (113).

Similarly, alginate-based hydrogels are used as a support material and investigated to treat ischemic and non-ischemic cardiomyopathy (NCT04781660). Lastly, a polyethylene glycol-based in situ crosslinked hydrogel (CoSeal ${ }^{\circledR}$ ) is under investigation for its applicability to prevent tissue inflammatory response caused by left ventricular assist device (LVAD). This hydrogel application is anticipated to avoid the inflammatory response and enable surgeons to remove VADs with minimal surgical interventions (NCT01244321) more easily.

The above-discussed clinical studies have demonstrated the efficacy of biomaterials. Their use as NPs, MPs, or hydrogels shows promise in treating CVD and can be employed in cardiac repair; however, there is a need for further investigation, innovation, and exploration of emerging smart biomaterials to impart therapeutic benefits.

\section{CONCLUSION}

Overall, the discovery of newer functionalized polymers provides an excellent potential for achieving sustained delivery of bioactive growth factors in treating the damaged heart. The availability of advanced techniques at our disposal for fabricating nanoparticles

\section{REFERENCES}

1. G.B.D. Mortality and causes of death, global, regional, and national life expectancy, all-cause mortality, and cause-specific mortality for 249 causes of death, 1980-2015: a systematic analysis for the Global Burden of Disease Study 2015. Lancet. (2016) 388:1459-544. doi: 10.1016/S0140-6736(16)31012-1

2. Leoni G, Soehnlein O. (Re) Solving repair after myocardial infarction. Front Pharmacol. (2018) 9:1342. doi: 10.3389/fphar.2018.01342

3. Prabhu SD, Frangogiannis NG. The biological basis for cardiac repair after myocardial infarction: from inflammation to fibrosis. Circ Res. (2016) 119:91-112. doi: 10.1161/CIRCRESAHA.116.303577

4. Zhao W, Zhao J, Rong J. Pharmacological modulation of cardiac remodeling after myocardial infarction. Oxid Med Cell Longev. (2020) 2020:8815349. doi: 10.1155/2020/8815349

5. Alexander JH, Smith PK. Coronary-artery bypass grafting. $N$ Engl J Med. (2016) 374:1954-64. doi: 10.1056/NEJMra1406944

6. Adair TH, Montani JP. Angiogenesis, Angiogenesis, Morgan \& Claypool Life Sciences. San Rafael, CA: Morgan \& Claypool Life Sciences (2010).

7. Reboucas JS, Santos-Magalhaes NS, Formiga FR. Cardiac regeneration using growth factors: advances and challenges. Arq Bras Cardiol. (2016) 107:271-5. doi: 10.5935/abc.20160097

8. Feng $\mathrm{Y}$, Wang $\mathrm{Y}$, Cao N, Yang H, Wang Y. Progenitor/stem cell transplantation for repair of myocardial infarction: Hype or hope? Ann Palliat Med. (2012) 1:65-77. doi: 10.3978/j.issn.2224-5820.2012.04.01

9. Greenhalgh DG. The role of growth factors in wound healing. J Trauma. (1996) 41:159-67. doi: 10.1097/00005373-199607000-00029

10. Hwang H, Kloner RA. The combined administration of multiple soluble factors in the repair of chronically infarcted rat myocardium. J Cardiovasc Pharmacol. (2011) 57:282-6. doi: 10.1097/FJC.0b013e3182058717 and microparticles has facilitated the ease of upscaling at the industrial level. These have also made it possible to control the size from nano to micro range with a great degree of spatiotemporal control, directly affecting drug release rate. In addition, the ever-growing field of biomaterials has demonstrated the possibility that smart hydrogels with sophisticated properties like electroconductivity have further expanded the spectrum of their application in the cardiac field. Another potential future application of these innovative biocompatible polymers could be localized immune-modulation, which can offer therapeutic potential in alleviating adverse immune reactions and aid in healing the damaged heart. The localized availability of therapeutic bioactive molecules has shown promising results in preclinical studies. Therefore, these therapies can further be explored in a clinical setting to facilitate the translation from bench to bedside.

\section{AUTHOR CONTRIBUTIONS}

SBA and MK: conceptualization and design. SBA, SA, DS, ZN, NP, HW, KB, WZ, NS, and MK: wrote and reviewed the manuscript. The input from all the authors was incorporated in finalizing the manuscript draft.

\section{ACKNOWLEDGMENTS}

This publication was supported by the National Heart, Lung, and Blood Institute of the National Institutes of Health under Award Number R01HL136232 (MK).
11. Simons M, Annex BH, Laham RJ, Kleiman N, Henry T, Dauerman H, et al. Pharmacological treatment of coronary artery disease with recombinant fibroblast growth factor-2: double-blind, randomized, controlled clinical trial. Circulation. (2002) 105:788-93. doi: 10.1161/hc0802.104407

12. Henry TD, Annex BH, McKendall GR, Azrin MA, Lopez JJ, Giordano FJ, et al. Investigators, The VIVA trial: Vascular endothelial growth factor in Ischemia for Vascular Angiogenesis. Circulation. (2003) 107:135965. doi: 10.1161/01.CIR.0000061911.47710.8A

13. Mir M, Ahmed N, Rehman AU. Recent applications of PLGA based nanostructures in drug delivery. Colloids Surf B Biointerfaces. (2017) 159:217-31. doi: 10.1016/j.colsurfb.2017. 07.038

14. Zielinska F, Carreiro AM, Oliveira A, Neves B, Pires DN, Venkatesh. et al. Polymeric nanoparticles: production, characterization, toxicology and ecotoxicology. Molecules. (2020) 25. doi: 10.3390/molecules25163731

15. Mohamed F, van der Walle CF. Engineering biodegradable polyester particles with specific drug targeting and drug release properties. J Pharm Sci. (2008) 97:71-87. doi: 10.1002/jps.21082

16. DeFrates K, Markiewicz T, Gallo P, Rack A, Weyhmiller A, Jarmusik B, et al. Protein polymer-based nanoparticles: fabrication and medical applications. Int J Mol Sci. (2018) 19. doi: 10.3390/ijms19061717

17. Uyen NTT, Hamid ZAA, Tram NXT, Ahmad N. Fabrication of alginate microspheres for drug delivery: A review. Int J Biol Macromol. (2020) 153:1035-46. doi: 10.1016/j.ijbiomac.2019.10.233

18. Masotti A, Ortaggi G. Chitosan micro- and nanospheres: fabrication and applications for drug and DNA delivery. Mini Rev Med Chem. (2009) 9:463-9. doi: 10.2174/138955709787847976

19. Kupikowska-Stobba B, Lewinska D. Polymer microcapsules and microbeads as cell carriers for in vivo biomedical applications. Biomater Sci. (2020) 8:1536-74. doi: 10.1039/C9BM01337G 
20. Gagliardi A, Giuliano E, Venkateswararao E, Fresta M, Bulotta S, Awasthi $\mathrm{V}$, et al. Biodegradable polymeric nanoparticles for drug delivery to solid tumors. Front Pharmacol. (2021) 12:601626. doi: 10.3389/fphar.2021.601626

21. Khan AR, Yang $\mathrm{X}, \mathrm{Fu}$ M, Zhai G. Recent progress of drug nanoformulations targeting to brain. J Control Release. (2018) 291:37-64. doi: 10.1016/j.jconrel.2018.10.004

22. Jenjob R, Phakkeeree T, Seidi F, Theerasilp M, Crespy D. Emulsion techniques for the production of pharmacological nanoparticles. Macromol Biosci. (2019) 19:e1900063. doi: 10.1002/mabi.201900063

23. Ding P, Chen L, Wei C, Zhou W, Li C, Wang J, et al. Cohen Stuart, and J Wang, Efficient Synthesis of Stable Polyelectrolyte Complex Nanoparticles by Electrostatic Assembly Directed Polymerization. Macromol Rapid Commun. (2021) 42:e2000635. doi: 10.1002/marc.202000635

24. Rafiei P, Haddadi A. A robust systematic design: Optimization and preparation of polymeric nanoparticles of PLGA for docetaxel intravenous delivery. Mater Sci Eng C Mater Biol Appl. (2019) 104:109950. doi: 10.1016/j.msec.2019.109950

25. Hu B, Pan C, Sun Y, Hou Z, Ye H, Zeng X. Optimization of fabrication parameters to produce chitosan-tripolyphosphate nanoparticles for delivery of tea catechins. J Agric Food Chem. (2008) 56:7451-8. doi: 10.1021/jf801111c

26. Huang W, Zhang C. Tuning the size of poly(lactic-co-glycolic acid) (plga) nanoparticles fabricated by nanoprecipitation. Biotechnol J. (2018) 13. doi: 10.1002/biot.201700203

27. Astete CE, Sabliov CM. Synthesis and characterization of PLGA nanoparticles. J Biomater Sci Polym Ed. (2006) 17:24789. doi: $10.1163 / 156856206775997322$

28. Roces CB, Christensen D, Perrie Y. Translating the fabrication of proteinloaded poly(lactic-co-glycolic acid) nanoparticles from bench to scaleindependent production using microfluidics. Drug Deliv Transl Res. (2020) 10:582-93. doi: 10.1007/s13346-019-00699-y

29. Choi WI, Sahu A, Vilos C, Kamaly N, Jo SM, Lee JH, et al. Bioinspired heparin nanosponge prepared by photo-crosslinking for controlled release of growth factors. Sci Rep. (2017) 7:14351. doi: 10.1038/s41598-017-14040-5

30. Liang Y, Kiick KL. Heparin-functionalized polymeric biomaterials in tissue engineering and drug delivery applications. Acta Biomater. (2014) 10:1588600. doi: 10.1016/j.actbio.2013.07.031

31. Polley P, Gupta S, Singh R, Pradhan A, Basu SM. Remya V, et al. Proteinsugar-glass nanoparticle platform for the development of sustained-release protein depots by overcoming protein delivery challenges. Mol Pharm. (2020) 17:284-300. doi: 10.1021/acs.molpharmaceut.9b01022

32. Ding WK, Shah NP. Effect of homogenization techniques on reducing the size of microcapsules and the survival of probiotic bacteria therein. J Food Sci. (2009) 74:M231-6. doi: 10.1111/j.1750-3841.2009.01195.x

33. Zhao H, Gagnon J, Hafeli UO. Process and formulation variables in the preparation of injectable and biodegradable magnetic microspheres. Biomagn Res Technol. (2007) 5:2. doi: 10.1186/1477-044X-5-2

34. Urbaniak $\mathrm{T}$, Musial W. Influence of solvent evaporation technique parameters on diameter of submicron lamivudine-poly-epsiloncaprolactone conjugate particles. Nanomaterials (Basel). (2019) 9. doi: 10.3390/nano9091240

35. Ravi S, Peh KK, Darwis Y, Murthy BK, Singh TR, Mallikarjun C. Development and characterization of polymeric microspheres for controlled release protein loaded drug delivery system. Indian J Pharm Sci. (2008) 70:303-9. doi: 10.4103/0250-474X.42978

36. Eng C, Cho S, Factor SM, Sonnenblick EH, Kirk ES. Myocardial micronecrosis produced by microsphere embolization. Role of an alphaadrenergic tonic influence on the coronary microcirculation. Circ Res. (1984) 54:74-82. doi: 10.1161/01.RES.54.1.74

37. Li W, Zhang L, Ge X, Xu B, Zhang W, Qu L. et al. Microfluidic fabrication of microparticles for biomedical applications. Chem Soc Rev. (2018) 47:564683. doi: 10.1039/C7CS00263G

38. Li X, Jiang X. Microfluidics for producing poly (lactic-co-glycolic acid)based pharmaceutical nanoparticles. Adv Drug Deliv Rev. (2018) 128:10114. doi: 10.1016/j.addr.2017.12.015

39. Somasekharan LT, Kasoju N, Raju R, Bhatt A. Formulation and characterization of alginate dialdehyde, gelatin, and platelet-rich plasmabased bioink for bioprinting applications. Bioengineering (Basel). (2020) 7:108. doi: 10.3390/bioengineering7030108
40. Fang R, Qiao S, Liu Y, Meng Q, Chen X, Song B, et al. Tian, Sustained co-delivery of BIO and IGF-1 by a novel hybrid hydrogel system to stimulate endogenous cardiac repair in myocardial infarcted rat hearts. Int J Nanomedicine. (2015) 10:4691-703. doi: 10.2147/IJN.S81451

41. Koivisto JT, Gering C, Karvinen J, Maria Cherian R, Belay B, Hyttinen $\mathrm{J}$, et al. Mechanically biomimetic gelatin-gellan gum hydrogels for 3D culture of beating human cardiomyocytes. ACS Appl Mater Interfaces. (2019) 11:20589-602. doi: 10.1021/acsami.8b22343

42. Karvinen J, Koivisto JT, Jonkkari I, Kellomaki M. The production of injectable hydrazone crosslinked gellan gum-hyaluronan-hydrogels with tunable mechanical and physical properties. J Mech Behav Biomed Mater. (2017) 71:383-91. doi: 10.1016/j.jmbbm.2017.04.006

43. Hasan A, Khattab A, Islam MA, Hweij KA, Zeitouny J, Waters R, et al. Injectable hydrogels for cardiac tissue repair after myocardial infarction. Adv Sci (Weinh). (2015) 2:1500122. doi: 10.1002/advs.201500122

44. Tang G, Tan Z, Zeng W, Wang X, Shi C, Liu Y. et al. Recent Advances of Chitosan-Based Injectable Hydrogels for Bone and Dental Tissue Regeneration. Front Bioeng Biotechnol. (2020) 8:587658. doi: 10.3389/fbioe.2020.587658

45. Alvi SB, Singh SP, Rengan AK. Chitosan-based thermosensitive hydrogel entrapping calcein for visualizing localized drug delivery. Proceedings of the Indian National Science Academy. (2021) 87:121-5. doi: 10.1007/s43538-021-00014-9

46. Gelain F, Luo Z, Rioult M, Zhang S. Self-assembling peptide scaffolds in the clinic. NPJ Regen Med. (2021) 6:9. doi: 10.1038/s41536-020-00116-w

47. Coin I, Beyermann M, Bienert M. Solid-phase peptide synthesis: from standard procedures to the synthesis of difficult sequences. Nat Protoc. (2007) 2:3247-56. doi: 10.1038/nprot.2007.454

48. Lin CC, Anseth KS. PEG hydrogels for the controlled release of biomolecules in regenerative medicine. Pharm Res. (2009) 26:63143. doi: 10.1007/s11095-008-9801-2

49. Choi JR, Yong KW, Choi JY, Cowie AC. Recent advances in photocrosslinkable hydrogels for biomedical applications. Biotechniques. (2019) 66:40-53. doi: 10.2144/btn-2018-0083

50. Lin-Gibson S, Bencherif S, Cooper JA, Wetzel SJ, Antonucci JM, Vogel $\mathrm{BM}$, et al. Synthesis and characterization of PEG dimethacrylates and their hydrogels. Biomacromolecules. (2004) 5:1280-7. doi: 10.1021/bm0498777

51. Morgacheva AA, Artyukhov AA, Panov AV, Gordienko MG, Shtil'man MI, Mezhuev YO. Synthesis of polyvinyl alcohol with methacrylate groups and of hydrogels based on it. Russian. J Applied Chemist. (2015) 88:61721. doi: 10.1134/S1070427215040102

52. Mitchell MJ, Billingsley MM, Haley RM, Wechsler ME, Peppas NA, Langer R. Engineering precision nanoparticles for drug delivery. Nat Rev Drug Discov. (2021) 20:101-24. doi: 10.1038/s41573-020-0090-8

53. Yu M, Wu J, Shi J, Farokhzad OC. Nanotechnology for protein delivery: Overview and perspectives. J Control Release. (2016) 240:2437. doi: 10.1016/j.jconrel.2015.10.012

54. Liu S, Chen X, Bao L, Liu T, Yuan P, Yang X, et al. Treatment of infarcted heart tissue via the capture and local delivery of circulating exosomes through antibody-conjugated magnetic nanoparticles. Nat Biomed Eng. (2020) 4:1063-75. doi: 10.1038/s41551-020-00637-1

55. Krohn-Grimberghe M, Mitchell MJ, Schloss MJ, Khan OF, Courties $\mathrm{G}$, et al. Nanoparticle-encapsulated siRNAs for gene silencing in the haematopoietic stem-cell niche. Nat Biomed Eng. (2020) 4:1076-89. doi: 10.1038/s41551-020-00623-7

56. O’Dwyer J, Cullen M, Fattah S, Murphy R, Stefanovic S, Kovarova $\mathrm{L}$, et al. Development of a sustained release nano-in-gel delivery system for the chemotactic and angiogenic growth factor stromal-derived factor 1alpha. Pharmaceutics. (2020) 12. doi: 10.3390/pharmaceutics120 60513

57. Ardestani MS, Bitarafan-Rajabi A, Mohammadzadeh P, MortazaviDerazkola S, Sabzevari O, Azar, et al. Synthesis and characterization of novel (99m)Tc-DGC nano-complexes for improvement of heart diagnostic. Bioorg Chem. (2020) 96:103572. doi: 10.1016/j.bioorg.2020.103572

58. Sayed N, Tambe P, Kumar P, Jadhav S, Paknikar KM, Gajbhiye V. miRNA transfection via poly(amidoamine)-based delivery vector prevents hypoxia/reperfusion-induced cardiomyocyte apoptosis. Nanomedicine (Lond). (2020) 15:163-81. doi: 10.2217/nnm-2019-0363 
59. Li WQ, Wu JY, Xiang DX, Luo SL, Hu XB, Tang TT, et al. Micelles loaded with puerarin and modified with triphenylphosphonium cation possess mitochondrial targeting and demonstrate enhanced protective effect against isoprenaline-induced $\mathrm{H} 9 \mathrm{c} 2$ cells apoptosis. Int J Nanomedicine. (2019) 14:8345-60. doi: 10.2147/IJN.S219670

60. Guo J, Xing X, Lv N, Zhao J, Liu Y, Gong H, et al. Therapy for myocardial infarction: In vitro and in vivo evaluation of puerarin-prodrug and tanshinone co-loaded lipid nanoparticulate system. Biomed Pharmacother. (2019) 120:109480. doi: 10.1016/j.biopha.2019.109480

61. Chen F, Zhao ER, Hableel G, Hu T, Kim T, Li J, et al. Increasing the Efficacy of Stem Cell Therapy via Triple-Function Inorganic Nanoparticles. ACS Nano. (2019) 13:6605-17. doi: 10.1021/acsnano.9b00653

62. Yokoyama R, Ii M, Masuda M, Tabata Y, Hoshiga M, Ishizaka N, et al. Cardiac Regeneration by Statin-Polymer Nanoparticle-Loaded AdiposeDerived Stem Cell Therapy in Myocardial Infarction. Stem Cells Transl Med. (2019) 8:1055-67. doi: 10.1002/sctm.18-0244

63. Huang Z, Song Y, Pang Z, Zhang B, Yang H, Shi H, et al. Targeted delivery of thymosin beta 4 to the injured myocardium using CREKA-conjugated nanoparticles. Int J Nanomedicine. (2017) 12:3023-36. doi: 10.2147/IJN.S131949

64. Chang MY, Yang YJ, Chang CH, Tang AC, Liao WY, Cheng FY, et al. Functionalized nanoparticles provide early cardioprotection after acute myocardial infarction. J Control Release. (2013) 170:287-94. doi: 10.1016/j.jconrel.2013.04.022

65. Tokutome M, Matoba T, Nakano Y, Okahara A, Fujiwara M, et al. Peroxisome proliferator-activated receptor-gamma targeting nanomedicine promotes cardiac healing after acute myocardial infarction by skewing monocyte/macrophage polarization in preclinical animal models. Cardiovasc Res. (2019) 115:419-31. doi: 10.1093/cvr/cvy200

66. Ruvinov E, Freeman I, Fredo R, Cohen S. Spontaneous coassembly of biologically active nanoparticles via affinity binding of heparin-binding proteins to alginate-sulfate. Nano Lett. (2016) 16:883-8. doi: 10.1021/acs.nanolett.5b03598

67. Quadros HC, Santos LMF, Meira CS, Khouri MI, Mattei B, Soares MBP, et al. Development and in vitro characterization of polymeric nanoparticles containing recombinant adrenomedullin2 intended for therapeutic angiogenesis. Int J Pharm. (2020) 576:118997. doi: 10.1016/j.ijpharm.2019.118997

68. Izadifar M, Kelly ME, Chen X. Regulation of sequential release of growth factors using bilayer polymeric nanoparticles for cardiac tissue engineering. Nanomedicine (Lond). (2016) 11:3237-59. doi: 10.2217/nnm-2016-0220

69. Johnson NR, Wang Y. Controlled delivery of sonic hedgehog morphogen and its potential for cardiac repair. PLoS ONE. (2013) 8:e63075. doi: 10.1371/journal.pone.0063075

70. Lin Y, Liu J, Bai R, Shi J, Zhu X, Liu J, et al. Mitochondriainspired nanoparticles with microenvironment-adapting capacities for ondemand drug delivery after ischemic injury. ACS Nano. (2020) 14:1184659. doi: 10.1021/acsnano.0c04727

71. Ye L, Zhang W, Su LP, Haider HK, Poh KK, Galupo MJ, et al. Nanoparticle based delivery of hypoxia-regulated VEGF transgene system combined with myoblast engraftment for myocardial repair. Biomaterials. (2011) 32:242431. doi: 10.1016/j.biomaterials.2010.12.008

72. Zhang Y, Khalique A, Du X, Gao Z, Wu J, Zhang X, et al. Biomimetic Design of Mitochondria-Targeted Hybrid Nanozymes as Superoxide Scavengers. Adv Mater. (2021) 33:e2006570. doi: 10.1002/adma.202006570

73. Nie H, Zhang Y, Yu H, Xiao H, Li T, Yang Q. Oral delivery of carrierfree dual-drug nanocrystal self-assembled microspheres improved $\mathrm{NAD}(+)$ bioavailability and attenuated cardiac ischemia/reperfusion injury in mice. Drug Deliv. (2021) 28:433-44. doi: 10.1080/10717544.2021.1886198

74. Feng J, Wu Y, Chen W, Li J, Wang X, Chen Y, et al. Sustained release of bioactive IGF-1 from a silk fibroin microsphere-based injectable alginate hydrogel for the treatment of myocardial infarction. J Mater Chem B. (2020) 8:308-315. doi: 10.1039/C9TB01971E

75. Zhang ZD, Xu YQ, Chen F, Luo JF, Liu CD. Sustained delivery of vascular endothelial growth factor using a dextran/poly(lactic-co-glycolic acid)combined microsphere system for therapeutic neovascularization. Heart Vessels. (2019) 34:167-76. doi: 10.1007/s00380-0181230-5
76. Song L, Ahmed MF, Li Y. PCL-PDMS-PCL Copolymerbased microspheres mediate cardiovascular differentiation from embryonic stem cells. Tissue Engineering Part C: Methods. (2017) 23:627-40. doi: 10.1089/ten.tec.2017.0307

77. Rodness J, Mihic A, Miyagi Y, Wu J, Weisel RD, Li RK. VEGF-loaded microsphere patch for local protein delivery to the ischemic heart. Acta Biomater. (2016) 45:169-81. doi: 10.1016/j.actbio.2016.09.009

78. Arunkumar P, Dougherty JA, Weist J, Kumar N, Angelos MG, Powell $\mathrm{HM}$, et al. Sustained release of basic fibroblast growth factor (bFGF) encapsulated polycaprolactone (PCL) microspheres promote angiogenesis in vivo. Nanomaterials (Basel). (2019) 9. doi: 10.3390/nano9071037

79. Formiga FR, Garbayo E, Diaz-Herraez P, Abizanda G, Simon-Yarza T, Tamayo E, et al. Biodegradation and heart retention of polymeric microparticles in a rat model of myocardial ischemia. Eur J Pharm Biopharm. (2013) 85:665-72. doi: 10.1016/j.ejpb.2013.02.017

80. Li Z, Hu S, Huang K, Su T, Cores J, Cheng K. Targeted anti-IL-1beta platelet microparticles for cardiac detoxing and repair. Sci Adv. (2020) 6:eaay0589. doi: 10.1126/sciadv.aay0589

81. Tang J, Shen D, Caranasos TG, Wang Z, Vandergriff AC, Allen TA, et al. Therapeutic microparticles functionalized with biomimetic cardiac stem cell membranes and secretome. Nat Commun. (2017) 8:13724. doi: $10.1038 /$ ncomms 13724

82. Pascual-Gil S, Abizanda G, Iglesias E, Garbayo E, Prosper F, Blanco-Prieto MJ. NRG1 PLGA MP locally induce macrophage polarisation toward a regenerative phenotype in the heart after acute myocardial infarction. J Drug Target. (2019) 27:573-81. doi: 10.1080/1061186X.2018.1531417

83. Formiga FR, Pelacho B, Garbayo E, Imbuluzqueta I, Diaz-Herraez P, Abizanda G, et al. Controlled delivery of fibroblast growth factor1 and neuregulin-1 from biodegradable microparticles promotes cardiac repair in a rat myocardial infarction model through activation of endogenous regeneration. J Control Release. (2014) 173:132-9. doi: 10.1016/j.jconrel.2013.10.034

84. Savi M, Bocchi L, Fiumana E, Karam JP, Frati C, Bonafe F, et al. Enhanced engraftment and repairing ability of human adipose-derived stem cells, conveyed by pharmacologically active microcarriers continuously releasing HGF and IGF-1, in healing myocardial infarction in rats. J Biomed Mater Res A. (2015) 103:3012-25. doi: 10.1002/jbm.a.35442

85. Zhang GW, Gu TX, Guan XY, Sun XJ, Qi X, Li XY, et al. HGF and IGF-1 promote protective effects of allogeneic BMSC transplantation in rabbit model of acute myocardial infarction. Cell Prolif. (2015) 48:66170. doi: $10.1111 /$ cpr.12219

86. Madonna R, Petrov L, Teberino MA, Manzoli L, Karam JP, Renna FV, et al. Transplantation of adipose tissue mesenchymal cells conjugated with VEGFreleasing microcarriers promotes repair in murine myocardial infarction. Cardiovasc Res. (2015) 108:39-49. doi: 10.1093/cvr/cvv197

87. Rosellini E, Barbani N, Frati C, Madeddu D, Massai D, Morbiducci $\mathrm{U}$, et al. IGF-1 loaded injectable microspheres for potential repair of the infarcted myocardium. J Biomater Appl. (2021) 35:762-75. doi: 10.1177/0885328220948501

88. Seshadri G, Sy JC, Brown M, Dikalov S, Yang SC, Murthy N, et al. The delivery of superoxide dismutase encapsulated in polyketal microparticles to rat myocardium and protection from myocardial ischemia-reperfusion injury. Biomaterials. (2010) 31:1372-9. doi: 10.1016/j.biomaterials.2009.10.045

89. Lu L, Yuan S, Wang J, Shen Y, Deng S, Xie L, et al. The Formation Mechanism of Hydrogels. Curr Stem Cell Res Ther. (2018) 13:4906. doi: 10.2174/1574888X12666170612102706

90. Shvartz V, Kanametov T, Sokolskaya M, Petrosyan A, Le T, Bockeria O, et al. Local Use of Hydrogel with Amiodarone in Cardiac Surgery: Experiment and Translation to the Clinic. Gels. (2021) 7. doi: 10.3390/gels7010029

91. Zhu D, Li Z, Huang K, Caranasos TG, Rossi JS, Cheng K. Minimally invasive delivery of therapeutic agents by hydrogel injection into the pericardial cavity for cardiac repair. Nat Commun. (2021) 12:1412. doi: 10.1038/s41467-021-21682-7

92. Malektaj H, Imani R, Siadati MH. Study of injectable PNIPAAm hydrogels containing niosomal angiogenetic drug delivery system for potential cardiac tissue regeneration. Biomed Mater. (2021) 16. doi: 10.1088/1748-605X/abdef8 
93. Radmanesh F, Sadeghi Abandansari H, Ghanian MH, Pahlavan S, Varzideh F, Yakhkeshi S, et al. Hydrogel-mediated delivery of microRNA-92a inhibitor polyplex nanoparticles induces localized angiogenesis. Angiogenesis. (2021) 24. doi: 10.1007/s10456-021-09778-6

94. Contessotto P, Orbanic D, Da Costa M, Jin C, Owens P, Chantepie S, et al. Elastin-like recombinamers-based hydrogel modulates post-ischemic remodeling in a non-transmural myocardial infarction in sheep. Sci Transl Med (2021) 13. doi: 10.1126/scitranslmed.aaz5380

95. Sim WS, Park BW, Ban K, Park HJ. In Situ Preconditioning of Human Mesenchymal Stem Cells Elicits Comprehensive Cardiac Repair Following Myocardial Infarction. Int J Mol Sci. (2021) 22. doi: 10.3390/ijms22031449

96. Lyu Y, Xie J, Liu Y, Xiao M, Li Y, Yang J. et al. Injectable Hyaluronic Acid Hydrogel Loaded with Functionalized Human Mesenchymal Stem Cell Aggregates for Repairing Infarcted Myocardium ACS Biomater Sci Eng. (2020) 6:6926-37. doi: 10.1021/acsbiomaterials.0c01344

97. You Y, Kobayashi K, Colak B, Luo P, Cozens E, Fields L, et al. Engineered cell-degradable poly(2-alkyl-2-oxazoline) hydrogel for epicardial placement of mesenchymal stem cells for myocardial repair. Biomaterials. (2021) 269:120356. doi: 10.1016/j.biomaterials.2020.120356

98. Ding J, Yao Y, Li J, Duan Y, Nakkala JR, Feng X, et al. A Reactive Oxygen Species Scavenging and $\mathrm{O} 2$ Generating Injectable Hydrogel for Myocardial Infarction Treatment In vivo. Small. (2020) 16:e2005038. doi: 10.1002/smll.202005038

99. Awada HK, Long DW, Wang Z, Hwang MP, Kim K, Wang Y. A single injection of protein-loaded coacervate-gel significantly improves cardiac function post infarction. Biomaterials. (2017) 125:65-80. doi: 10.1016/j.biomaterials.2017.02.020

100. Tang J, Cui X, Caranasos TG, Hensley MT, Vandergriff AC, Hartanto Y, et al. Heart repair using nanogel-encapsulated human cardiac stem cells in mice and pigs with myocardial infarction. ACS Nano. (2017) 11:973849. doi: 10.1021/acsnano.7b01008

101. Kanda P, Alarcon EI, Yeuchyk T, Parent S, Kemp RAde, Variola F, et al. Deterministic encapsulation of human cardiac stem cells in variable composition nanoporous gel cocoons to enhance therapeutic repair of injured myocardium. ACS Nano. (2018) 12:4338-50. doi: 10.1021/acsnano.7b08881

102. Yang H, Qin X, Wang H, Zhao X, Liu Y, Wo HT, et al. An in vivo miRNA delivery system for restoring infarcted myocardium. ACS Nano. (2019) 13:9880-94. doi: 10.1021/acsnano.9b03343

103. Li Z, Zhu D, Hui Q, Bi J, Yu B, Huang Z, et al. Injection of ROS-responsive hydrogel loaded with basic fibroblast growth factor into the pericardial cavity for heart repair. Adv Funct Mater. (2021) 31:2004377. doi: 10.1002/adfm.202004377

104. Lin YD, Chang MY, Cheng B, Liu YW, Lin LC, Chen JH, et al. Injection of Peptide nanogels preserves postinfarct diastolic function and prolongs efficacy of cell therapy in pigs Tissue. Eng Part A. (2015) 21:166271. doi: 10.1089/ten.tea.2014.0581

105. Bai R, Tian L, Li Y, Zhang J, Wei Y, Jin Z, et al. Combining ECM Hydrogels of Cardiac Bioactivity with Stem Cells of High Cardiomyogenic Potential for Myocardial Repair. Stem Cells Int. (2019) 2019:6708435. doi: 10.1155/2019/6708435
106. Dong R, Zhao X, Guo B, Ma PX. Self-healing conductive injectable hydrogels with antibacterial activity as cell delivery carrier for cardiac cell therapy. ACS Appl Mater Interfaces. (2016) 8:17138-50. doi: 10.1021/acsami.6b 04911

107. Liao S-H, Huang H-S, Chen J-H, Su Y-K, Tong Y-F. Characterization of magnetic relaxation when biofunctionalized magnetic nano-particles are associated with biomarkers in the liquid state in biomedical applications. RSC Adv. (2018) 8:4057-62. doi: 10.1039/C7RA12634D

108. Kharlamov AN, Tyurnina AE, Veselova VS, Kovtun OP, Shur VY, et al. Silica-gold nanoparticles for atheroprotective management of plaques: results of the NANOM-FIM trial. Nanoscale. (2015) 7:800315. doi: 10.1039/C5NR01050K

109. Kharlamov AN, Feinstein JA, Cramer JA, Boothroyd JA, Shishkina EV, Shur V. Plasmonic photothermal therapy of atherosclerosis with nanoparticles: long-term outcomes and safety in NANOM-FIM trial. Future Cardiol. (2017) 13:345-63. doi: 10.2217/fca-2017-0009

110. Wu J, Xie F, Lof J, Sayyed S, Porter TR. Utilization of modified diagnostic ultrasound and microbubbles to reduce myocardial infarct size. Heart. (2015) 101:1468-74. doi: 10.1136/heartjnl-2015-307625

111. Tardif JC, Kouz S, Waters DD, Bertrand OF, Diaz R, Maggioni AP, et al. Efficacy and Safety of Low-Dose Colchicine after Myocardial Infarction. N Engl J Med. (2019) 381:2497-505. doi: 10.1056/NEJMoa19 12388

112. Bulgarelli, Leite AC, Jr, Dias AA, Maranhao RC. Anti-atherogenic effects of methotrexate carried by a lipid nanoemulsion that binds to LDL receptors in cholesterol-fed rabbits. Cardiovasc Drugs Ther. (2013) 27:5319. doi: 10.1007/s10557-013-6488-3

113. Takehara N, Tsutsumi Y, Tateishi K, Ogata T, Tanaka H, Ueyama T, et al. Controlled delivery of basic fibroblast growth factor promotes human cardiosphere-derived cell engraftment to enhance cardiac repair for chronic myocardial infarction. J Am Coll Cardiol. (2008) 52:185865. doi: 10.1016/j.jacc.2008.06.052

Conflict of Interest: The authors declare that the research was conducted in the absence of any commercial or financial relationships that could be construed as a potential conflict of interest.

Publisher's Note: All claims expressed in this article are solely those of the authors and do not necessarily represent those of their affiliated organizations, or those of the publisher, the editors and the reviewers. Any product that may be evaluated in this article, or claim that may be made by its manufacturer, is not guaranteed or endorsed by the publisher.

Copyright (c) 2021 Alvi, Ahmed, Sridharan, Naseer, Pracha, Wang, Boudoulas, Zhu, Sayed and Khan. This is an open-access article distributed under the terms of the Creative Commons Attribution License (CC BY). The use, distribution or reproduction in other forums is permitted, provided the original author(s) and the copyright owner(s) are credited and that the original publication in this journal is cited, in accordance with accepted academic practice. No use, distribution or reproduction is permitted which does not comply with these terms. 